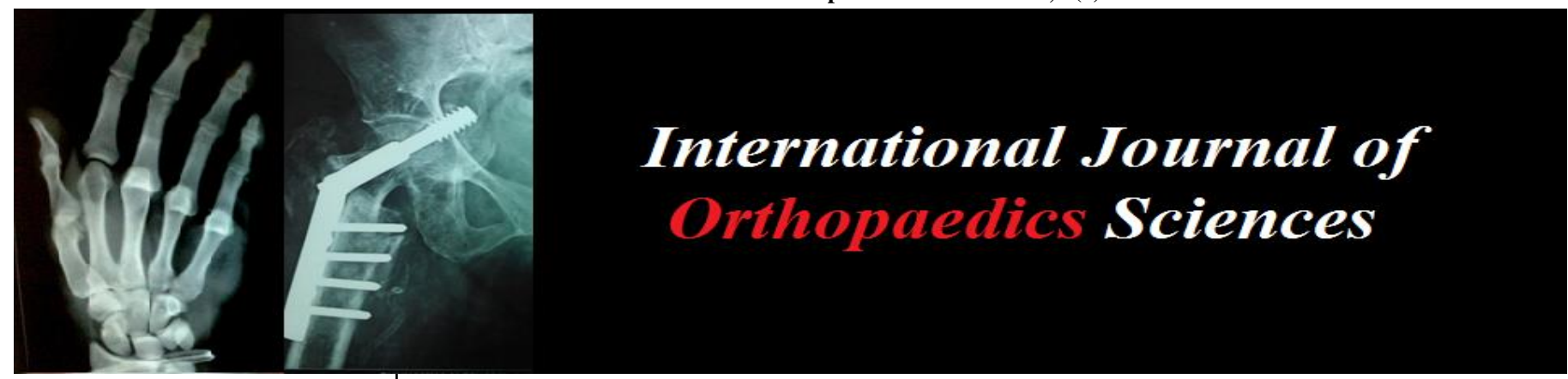

E-ISSN: 2395-1958

P-ISSN: 2706-6630

IJOS 2020; 6(1): 1351-1355

(C) $2020 \mathrm{IJOS}$

www.orthopaper.com

Received: 19-11-2019

Accepted: 05-01-2020

Varun Gautam

MBBS, DNB (Orthopaedics)

Senior Resident, Department of Orthopaedics, Kalpana Chawla

Govt. Medical College, Karnal,

Haryana, India

Prateek Girotra

MBBS, DNB (Orthopaedics)

Senior Resident, Hindu Rao

Hospital, Delhi, India

Anu Nagpal

Consultant, Obstetrics and

Gynaecology, Nagpal Nursing

Home, Gurgaon, Haryana, India
Corresponding Author:

Prateek Girotra

MBBS, DNB (Orthopaedics)

Senior Resident, Hindu Rao

Hospital, Delhi, India

\section{Arthroscopic assisted mini-open single row repair of rotator cuff tears: a quality of life impairment study}

\author{
Varun Gautam, Prateek Girotra and Anu Nagpal
}

DOI: https://doi.org/10.22271/ortho.2020.v6.i1r.3013

\section{Abstract}

Introduction: The present study was conducted to assess the clinical, functional and quality of life related outcome of rotator cuff repair performed using an arthroscopic assisted mini-open repair technique.

Methodology: A prospective study was conducted in Department of Orthopaedics, BPS Government Medical College and Hospital, in which patients, aged 30 to 70 years, who had an isolated tear in the rotator cuff tendon diagnosed by clinical examination \& confirmed by MRI and had cuff repair performed solely with the use of arthroscopic assisted mini-open technique were included. Shoulder function assessments were made with University of California at Los Angeles (UCLA) rating scale and Short Form Health Survey questionnaire (SF-36).

Results: Mean age of the 26 patients included was $47.12 \pm 10.72$ years. Most common mode of injury in our patient population was domestic fall, reported by $84.6 \%$ of the patients. Road side accident was reported by three patients and sports injury by one. Partial thickness tear was observed in $57.7 \%$ of the patients and rest had a full thickness tear. We found the UCLA score reduced significantly from

$12.42 \pm 3.7$ preoperatively to $29.46 \pm 3.01$ at the end of 6 months. There is significant improvement in range of motion at the last follow up. Forward flexion averaged $84^{\circ}$ (SD 32 , 95\% CI 73-96 ${ }^{\circ}$ ) preoperatively and $120^{\circ}\left(\mathrm{SD} 21^{\circ}, 95 \% \mathrm{CI} 112-127^{\circ}\right)$ at the last follow-up $(\mathrm{P}<.0 .001)$. External rotation improved from a mean of $81^{\circ}\left(\mathrm{SD} 7.8^{\circ}, 95 \%\right.$ CI $\left.79-84^{\circ}\right)$ preoperatively to a mean of $99^{\circ}(\mathrm{SD} 15,95 \%$ CI $\left.94-105^{\circ}\right)$ at the latest follow-up $(\mathrm{P}<.0 .001)$. The mean internal rotation improved from $28^{\circ}$ (SD $2^{\circ}, 95 \%$ CI $28-29^{\circ}$ ) at baseline to $33^{\circ}$ (SD 3, 95\% CI 31-34 ) at the latest follow-up (P<.0.001).SF36 scores showed a significant improvement in all the subscales as well.

Conclusions: There is significant improvement in the quality of life both physically and mentally, as measured using the SF-36 self administered questionnaire and there is significant improvement in range of motion and functional status as measured by UCLA score after performing an arthroscopic assisted mini-open rotator cuff repair.

Keywords: Mini-open, arthroscopic repair, shoulder, clinical outcomes

\section{Introduction}

Rotator cuff pathology is an important determinant of overall health status, with a marked impact on an individual's quality of life. It is a painful condition with a multi- factorial etiology in which severe or chronic impingement of the rotator cuff tendons on the undersurface of the coracoacromial arch is often a significant factor ${ }^{[1]}$. Conservative therapy is the first treatment approach for patients with rotator cuff tears. However, surgery is indicated when conservative management fails or in cases of a large to massive tears. Mini-open repairs were developed because they had the potential advantage of less deltoid morbidity, and demonstrated clinical outcomes that have been similar to those of open repairs. Treatment protocols after repair are decided by surgeons and depend on the tendon repaired, healing time of that tendon and preferences by surgeons. Creating an optimal treatment protocol would benefit from evidence-based information on factors that predict prognosis after rotator cuff repair and quantified evidence on improvements in shoulder function in terms of muscle performances and range of motion which is lacking in the literature.

We evaluated the effectiveness in term of patient's status and quality of life in patients who underwent arthroscopic assisted mini-open rotator cuff repair in our department. 


\section{Material and Methods}

Thirty-eight women with low energy hip fractures from the women admitted to our institution.

\section{Methodology \\ Study design and sampling}

A prospective study was conducted in Department of Orthopaedics, BPS Government Medical College and Hospital for twelve months. We included patients, aged 30 to 70 years, who had an isolated tear in the rotator cuff tendon diagnosed by clinical examination \& confirmed by MRI and had cuff repair performed solely with the use of arthroscopic assisted miniopen technique. Patients presenting with complaints of shoulder pain, weakness in elevation and difficulty in abduction of shoulder were evaluated clinically. Those suspected of rotator cuff tear were referred for MRI study on a $1.5 \mathrm{~T}$ scanner. A full-thickness tear of the rotator cuff was diagnosed on MRI by the presence of a complete discontinuity or gap in the tendon, or if there was an increased signal intensity (isointense compared to fluid), extending from the articular to the bursal surface of the tendon, was found on T2-weighted images. The study was conducted in 26 patients. The sample size was calculated based on previous studies by Vaidyar $\mathrm{J}$ et al. ${ }^{[2]}$. With the power of study being $90 \%$ and alpha error at 5\%, sample proportion 0.25 and with confidence interval $95 \%$ the sample size was calculated to be 26 patients. Patients having associated shoulder lesions, those undergoing revision rotator cuff repair patients, those with irreparable tears (massive tear $>5 \mathrm{~cm}$ with retraction \& fatty infiltration of muscle), with associated symptomatic acromioclavicular arthritis, with associated biceps brachii tendon pathology or with with cuff tear arthropathy were excluded from the study.

\section{Surgical technique and post-operative rehabilitation}

Arthroscopic glenohumeral examination was performed to evaluate intra articular pathology and subacromial decompression, an anterio-lateral approach was used for tear exposure. A 3-4 $\mathrm{cm}$ skin incision was made from the anterolateral edge of the acromion distally. An anterior/inferior acromioplasty was performed. After partial bursectomy and limited debridement of tendon margins, the rotator cuff was mobilized with the arm at the side until full coverage of the footprint without undue tension was achieved. Tendon-to-bone repair was performed with single row technique using suture anchors. Two sets of size $5 \mathrm{~mm}$ double loaded anchor sutures were used, depending on the size of the tear. Deltoid was repaired meticulously using absorbable sutures. The operated arm was placed at the side in a sling with a small pillow. The sling was worn continuously for 6 weeks, except during bathing and exercises. The standard postoperative rehabilitation program included immobilization with sling for first 6 weeks, active range of motion of shoulder, avoiding lateral abduction for next 6 weeks, strengthening of deltoid, biceps, triceps, rotator cuff after 12 weeks post-operatively and resumption of normal activities after 6 months post-operatively.

\section{Data Collection and Data Analysis Evaluation}

Using a pre-designed case report form, demographic and clinical information was noted for all patients. An author not involved in the surgical procedure performed all the outcome assessments. We performed preoperative evaluations the day before surgery and report the results of postoperative evaluation at 2 weeks, 8 weeks, 12 weeks and 24 weeks six months after the operation. Each patient was evaluated for pre- and postoperative range of motion (ROM), pre- and postoperative modified shoulder score (UCLA), as well as pre- and postoperative SF-36 self administered questionnaire.

\section{Imaging}

All patients received a standard preoperative assessment using standard radiographs (anteroposterior projections, neutral, external and internal rotation) and MRI scans (Oblique coronal, oblique sagittal and axial T2-weighted

MRIs were obtained in all patients).

\section{Functional assessment}

Functional status of the patients was assessed by a modified University of California, Los Angeles (UCLA) ${ }^{[3]}$ rating scale for pain, function, ROM, and patient satisfaction UCLA preoperatively, postoperatively 2 weeks, 8 weeks, 12 weeks and 24 weeks were noted. The UCLA Shoulder Score is a 35point scale consisting of 10 points for pain, 10 points for function, and 5 points each for motion, strength, and patient satisfaction. The maximum score obtainable was

35 , and the results were classified as excellent (34-35), good (28-33), fair (21-27), or poor (0-20). A higher score indicates increased shoulder function.

\section{Range of motion}

The shoulder range of motion (forward elevation, external rotation and internal rotation) was recorded preoperatively and at six months and two years after the surgery. Measurements were made, following standard guidelines, in the supine position with the scapula stabilised by anterior pressure on the shoulder against the examining table. The examiner obtained three measurements for each shoulder, and the mathematical mean was used for statistical purposes.

\section{Quality of life (SF 36)}

To assess the quality of life impairment we used the SF-36, a 36 item Short Form Health Survey questionnaire (SF-36) ${ }^{[4]}$ which is widely used to measure health status. Scores for each item range from 0 (poor) to 100 (good) ${ }^{[4]}$.

\section{Statistics}

Data were entered and analysed using SPSS software (version 21 for Windows). Quantitative data were expressed as mean and standard deviation and qualitative as number and percentage. Means of UCLA scale score and SF36 scores at different time points in the follow up period were compared using the repeat measure analysis of variance (ANOVA) test, followed by a post-hoc test. All the results were considered to be significant at the $5 \%$ critical level.

\section{Results}

There were a total of 26 patients included in the study. Mean age of the patients was $47.12 \pm 10.72$ years, the most common age group being 40 to 50 years and females comprised $61.5 \%$ of the study population (Table 1). More than half of all patients were housewives and did home work. Other than that five patients were farmers, three were shop owners and one each were driver, teacher and a wrestler. Most common mode of injury in our patient population was domestic fall, reported by $84.6 \%$ of the patients. Road side accident was reported by three patients and sports injury by one. Dominant hand was right in $73.1 \%$ of the patients. Affected side was right in $65.4 \%$ of the patients. Partial thickness tear was observed in $57.7 \%$ of the patients and rest had a full thickness tear. Only three patients reported persistent pain and stiffness of shoulder and one reported only stiffness of shoulder. Rest of the patients $(n=22)$ reported no complications post 
operatively. On clinical evaluation (table 3) the range of motion of the affected shoulder improved from the baseline to last follow-up. Forward flexion averaged $84^{\circ}$ (SD 32, $95 \%$ CI 73-96 ${ }^{\circ}$ ) preoperatively and $120^{\circ}$ (SD $21^{\circ}$, 95\% CI $112-$ $\left.127^{\circ}\right)$ at the last follow-up $(\mathrm{P}<.0 .001)$. External rotation improved from a mean of $81^{\circ}\left(\mathrm{SD} 7.8^{\circ}, 95 \%\right.$ CI $79-84^{\circ}$ ) preoperatively to a mean of $99^{\circ}\left(\mathrm{SD} 15,95 \%\right.$ CI $\left.94-105^{\circ}\right)$ at the latest follow-up $(\mathrm{P}<.0 .001)$. The mean internal rotation improved from $28^{\circ}\left(\operatorname{SD} 2^{\circ}, 95 \%\right.$ CI $\left.28-29^{\circ}\right)$ at baseline to $33^{\circ}$ (SD 3, 95\% CI 31-34 $)$ at the latest follow-up (P<.0.001).

We found that the UCLA score preoperatively was $12.42 \pm$ 3.7 (range 8 to 21 ) which reduced significantly to $29.46 \pm$ 3.01 (range 21 to 33) at the end of 6 months. SF36 scores for different components have been described in Table 4 as well. The SF-36 demonstrated a significant improvement in comparison to their preoperative scores $(\mathrm{P}<0.001)$.

Table 1: Baseline characteristics of the patients included in the study

\begin{tabular}{|c|c|}
\hline Variables & $\mathbf{N}(\%)$ \\
\hline Age group (in years) & $08(30.8)$ \\
\hline Less than 40 & $10(38.5)$ \\
\hline 41 to 50 & $04(15.4)$ \\
\hline S0 to 60 & $04(15.4)$ \\
\hline More than 60 & $16(61.5)$ \\
\hline Gender distribution & $10(38.5)$ \\
\hline Memale & $01(3.8)$ \\
\hline Occupation & $05(15.4)$ \\
\hline Driver & $15(57.7)$ \\
\hline Farmer & $03(11.5)$ \\
\hline Housewife & $01(3.8)$ \\
\hline Shopowner & $01(3.8)$ \\
\hline Teacher & \\
\hline Wrestling & $07(26.9)$ \\
\hline Dominant hand & $19(73.1)$ \\
\hline Left & \\
\hline
\end{tabular}

Table 2: Characteristics of the rotator cuff injury in our study population

\begin{tabular}{|c|c|}
\hline Variables & $\mathbf{N}(\%)$ \\
\hline Mode of injury & $22(84.6)$ \\
\hline Domestic fall & $03(11.5)$ \\
\hline Road side accident & $01(3.8)$ \\
\hline Sports injury & $09(34.6)$ \\
\hline Affected side & $17(65.4)$ \\
\hline Left & \\
\hline Right & $11(42.3)$ \\
\hline Full thickness & $13(57.7)$ \\
\hline Partial Thickness & \\
\hline Post-operative complications & $22(84.6)$ \\
\hline Persistentpain and stiffness & $03(11.5)$ \\
\hline Stiffness & $01(3.8)$ \\
\hline
\end{tabular}

Table 3: Clinical evaluationa

\begin{tabular}{|c|c|c|}
\hline Evaluation & Pre-Operativelyb & At 6th Month Follow Upb \\
\hline Forward Flexionc (Deg) & $84(32 ; 73-96)$ & $120(21 ; 112-127)$ \\
\hline External Rotationc (Deg) & $81(8 ; 79-84)$ & $99(15 ; 94-105)$ \\
\hline Internal Rotationc (Deg) & $28(2 ; 28-29)$ & $33(3 ; 31-34)$ \\
\hline Uclac & $12.42 \pm 3.7$ (Range 8 To 21) & 29.46 \\
\hline
\end{tabular}

a. $\quad$ Analysed using repeated-measures analysis of variance. The values given as mean score (SD; $95 \% \mathrm{CI})$

b. $\quad \mathrm{P}<0.001$ between baseline and latest follow-up

Table 4: Quality of life (SF-36) Outcome

\begin{tabular}{|c|c|c|c|c|c|}
\hline \multirow{2}{*}{ Measure } & \multicolumn{2}{|c|}{ Pre-operatively } & & \\
\cline { 2 - 5 } & Mean & SD & Mean & SD & \\
\hline Physical functioning & 44.04 & 5.10 & 70.19 & 6.55 & $<0.01$ \\
\hline Role-Physical & 29.81 & 10.05 & 62.50 & 12.75 & $<0.01$ \\
\hline Role-Emotional & 28.19 & 20.43 & 79.49 & 25.09 & $<0.01$ \\
\hline Energy/Fatigue & 39.62 & 5.08 & 70.19 & 7.14 & $<0.01$ \\
\hline Emotional Well- being & 46.15 & 3.79 & 77.23 & 7.98 & $<0.01$ \\
\hline Social Functioning & 31.25 & 7.29 & 67.79 & 11.28 & $<0.01$ \\
\hline Bodily Pain & 32.79 & 6.42 & 72.88 & 12.22 & $<0.01$ \\
\hline General Health & 34.23 & 3.92 & 73.65 & 5.01 & $<0.01$ \\
\hline
\end{tabular}




\section{Discussion}

The present study assessed the quality of life impairment of rotator cuff tear patients who underwent arthroscopic assisted mini-open repair. Most common mode of injury in our patients was domestic fall, reported by $84.6 \%$ of the patients. Road side accident was reported by three patients and sports injury by one. The cause of rotator cuff tears is likely multifactorial. Degeneration, impingement, and overload may all contribute in varying degrees to the development of rotator cuff tears. Several theories have been developed to explain the cause of rotator cuff injury. In 1934, Codman theorized that rotator cuff tears developed from intrinsic tissue degeneration [5]. More than half of all tears in our study were partial thickness. Most often rotator cuff lesions appear to start as partial tears of the undersurface or articular portion of the supraspinatus tendon ${ }^{[6]}$. Over time they can progress to full thickness tears to include the supraspinatus, infraspinatus, Subscapularis and biceps tendons. The appropriate indications for surgery to treat rotator cuff tears remain debatable among orthopedic surgeons ${ }^{[7]}$. In most cases, surgery is considered only when conservative measures fail. One important exception to this principle is an acute, full thickness traumatic tear of an otherwise normal rotator cuff in a healthy individual. Such an injury is usually treated with immediate surgery, since delay can lead to significant muscle atrophy, tendon retraction, and poorer surgical results. The mini-open rotator cuff repair became popular in recently and remains an acceptable approach for surgeons who are unfamiliar or uncomfortable with arthroscopic surgical techniques. This approach involves a substantially smaller incision and exposure than that of an open approach. Moreover, the results achieved using mini-open cuff repair with arthroscopic subacromial decompression appear equal to those of open reconstruction ${ }^{[8]}$. All the patients in our study got single row suture-anchor repair. Previous studies have shown that the repair technique plays an important part in tendon to bone healing of these tears, as healing without gap formation is a major factor in restoring post-operative function [9]. While, Burkhart et al. ${ }^{[10]}$ showed that fixation by suture anchors is stronger than by trans-osseous tunnels, Barber, Herbert and Click ${ }^{[11]}$ stated that all available biodegradable suture anchors have adequate pull-out strength to resist physiological loads. A two-row repair has been shown to be superior to one-row, with better recreation of the footprint, higher resistance to cyclic displacement, increased stiffness and ultimate load to failure ${ }^{[12]}$. The modified Mason-Allen stitch was first described by Gerber et al. ${ }^{[13]}$ and was found to have a higher tensile strength than simple mattress sutures.

Nho and colleagues have highlighted the difficulty in comparing rotator cuff tear repairs as it is still unclear which primary outcome defines success of the procedure ${ }^{[14]}$. We used UCLA score in the present study, which is one of the most commonly scoring system used for assessing shoulder function. We observed a significant improvement in the mean UCLA score from preoperative score of $12.42 \pm 3.7$ to 29.46 \pm 3.01 at 24 weeks. Similar significant improvements in the UCLA score with mini-open technique has been described by Saridakis and Jones in their meta-analysis ${ }^{[15]}$. On the SF-36 scale, our patients showed significant improvement in all subscales as well. Chung et al studied 309 patients to evaluate the outcomes of arthroscopic rotator cuff repair and observed improvement in all subscales of SF36, except general health perception ${ }^{[16]}$. Baysal et al. ${ }^{[17]}$ demonstrated that mini-open repair of a full-thickness tear improved the postoperative quality of life as measured by the Western Ontario Rotator
Cuff Index scores; Vitale et al. ${ }^{[18]}$ also reported postoperative increases in the Health Utility Index and the European Quality of Life Measure, suggesting that rotator cuff repair is a highly cost-effective intervention in health care. Gartsman et al. ${ }^{[19]}$ showed that arthroscopic repair of a full-thickness rotator cuff tear in 50 consecutive patients improved SF-36 scores at the most recent follow- up from 34.1 preoperatively to 46.5 in the physical component score and from 49.7 preoperatively to 52.6 in the mental component score.

\section{Conclusion}

Our results show that arthroscopic mini-open rotator cuff repair is a successful procedure for improving patients' quality of life, both physically and mentally, as measured using the SF-36. As arthroscopic techniques develop, it will be important to continually compare the new results with the standards that have been established for the rotator cuff repair.

\section{References}

1. Gray H, Standring S. Gray's anatomy: the anatomical basis of clinical practice. Churchill Livingstone, 2008.

2. Vaidyar J, Kassim S, Shibli S, Safwan U. Functional Outcome of Shoulder Following Mini-open Repair for Rotator cuff Injuries. Int. J Cur Res Rev. 2015;7(7):40-4

3. Gartsman GM, Brinker MR, Khan M. Early effectiveness of arthroscopic repair for full-thickness tears of the rotator cuff: an outcome analysis. JBJS. 1998;80(1):33-40.

4. Ware JE. SF-36 health survey: manual and interpretation guide. Health Institute. 1993.

5. McFarland EG. Examination of the shoulder. In: The Complete Guide, Kim TK, Park HB, Rassi GE et al. (Eds), Thieme Medical Publishers, New York. 2006, 142.

6. Oh LS, Wolf BR, Hall MP et al. Indications for rotator cuff repair: a systematic review. Clin Orthop Relat Res. 2007;455:52.

7. Dunn WR, Schackman BR, Walsh C, et al. Variation in orthopaedic surgeons' perceptions about the indications for rotator cuff surgery. J Bone Joint Surg Am. 2005;87:1978.

8. Mohtadi NG, Hollinshead RM, Sasyniuk TM, et al. A randomized clinical trial comparing open to arthroscopic acromioplasty with mini-open rotator cuff repair for fullthickness rotator cuff tears: disease-specific quality of life outcome at an average 2-year follow-up. Am J Sports Med. 2008;36:1043.

9. Schneeberger AG, Von Roll A, Kalberer F, Jacob HA, Gerber C. Mechanical strength of arthroscopic rotator cuff repair techniques: an in vivo study. JBJS. 2002; 84(12):2152-60.

10. Burkhart SS, Diaz Pagà n JL, Wirth MA, Athanasiou KA. Cyclic loading of anchor-based rotator cuff repairs: confirmation of the tension overload phenomenon and comparison of suture anchor fixation with Trans osseous fixation. Arthroscopy. 1997;13(6):720-4.

11. Barber FA, Herbert MA, Click JN. Internal fixation strength of suture anchors: update. Arthroscopy. 1997; 13(3):355-62.

12. Milano G, Grasso A, Zarelli D. Comparison between single-row and double- row rotator cuff repairs: a biomechanical study. Knee Surgery Sports Traumatology Arthroscopy. 2008;16(1):75-80.

13. Gerber C, Schneeberger AG, Beck M, Schlegel U. Mechanical strength of repairs of the rotator cuff. The Journal of bone and joint surgery British. 1994;76(3):37180. 
14. Nho SJ, Shindle MK, Sherman SL, Freedman KB, Lyman S, MacGillivray JD. Systematic review of arthroscopic rotator cuff repair and mini-open rotator cuff repair. JBJS. 2007;89:127-36.

15. Saridakis P, Jones G. Outcomes of single-row and doublerow arthroscopic rotator cuff repair: a systematic review. JBJS. 2010;92(3):732-42.

16. Chung SW, Park JS, Kim SH, Shin SH, Oh JH. Quality of life after arthroscopic rotator cuff repair: evaluation using SF-36 and an analysis of affecting clinical factors. The American journal of sports medicine. 2012;40(3):631-9.

17. Baysal D, Balyk R, Otto D, Luciak-Corea C, Beaupre L. Functional outcome and health-related quality of life after surgical repair of full-thickness rotator cuff tear using a mini-open technique. Am J Sports Med. 2005; 33(9):1346-1355.

18. Vitale MA, Vitale MG, Zivin JG, Braman JP, Bigliani LU, Flatow EL. Rotator cuff repair: an analysis of utility scores and cost-effective- ness. J Shoulder Elbow Surg. 2007;16(2):181-187.

19. Gartsman GM, Brinker MR, Khan M. Early effectiveness of arthroscopic repair for full-thickness tears of the rotator cuff: an outcome analysis. J Bone Joint Surg Am. 1998; 80(1):33-40. 